\title{
Custos da qualidade: a experiência de um restaurante potiguar no Programa Turismo Melhor
}

\author{
Valdério Freire Moraes Júnior \\ Mestrado em Ciências Contábeis pela Universidade de Brasília - UNB \\ Professor da Faculdade Natalense - FARN \\ FARN. Natal/RN. CEP: 59000-000 \\ E-mail: valderiofreire@yahoo.com.br \\ Adriana Fernandes Vasconcelos \\ Mestrado em Ciências Contábeis pela Universidade de Brasília - UNB \\ Professora da Faculdade do Vale do Ipojuca - FAVIP \\ Rua Adjar da Silva Casé, 800. Indianápolis. Caruaru/PE. CEP: 55024-901 \\ E-mail: adrivasconcelos@hotmail.com
}

Claudia Gomes Graciano Universidade Federal do Rio Grande do Norte - UFRN Av. Senador Salgado Filho. S/N. Campus Universitário - DCC. Natal/RN. CEP: 59076000 E-mail: claudiagomesgomes@yahoo.com.br

Aneide Oliveira Araújo Doutorado em Ciências Contábeis pela Universidade de São Paulo - USP Professora da Universidade Federal do Rio Grande do Norte - UFRN Av. Senador Salgado Filho. S/N. Campus Universitário - DCC. Natal/RN. CEP: 59076000 E-mail: aneide@ufrnet.br

\section{RESUMO}

Custos da qualidade geralmente estão relacionados a prevenção, falhas internas, falhas externas e inspeção. Esses custos devem ser gerenciados, e por esta razão as empresas têm buscado a implementação de programas de qualidade, com o intuito de melhorar seus produtos e serviços, bem como para aumentar seus lucros. Nessa perspectiva, o presente estudo tem como objetivo analisar os custos de qualidade de um restaurante potiguar localizado na cidade do Natal, que aderiu ao Programa Turismo Melhor em 2006. Trata-se de uma investigação de natureza qualitativa sobre a mensuração dos custos de qualidade com base no período de janeiro de 2006 a maio de 2007. Os dados foram obtidos por meio de entrevista semi-estruturada bem como de relatórios contábeis para verificação das relações existentes entre as variáveis que integram os custos da qualidade da empresa. Os resultados mostram que a adesão ao selo trouxe benefícios à entidade pela redução efetiva de falhas percebidas no primeiro semestre de 2007, fixação em um mercado cada vez mais competitivo e melhores 
Custos da qualidade: a experiência de um restaurante potiguar no Programa Turismo Melhor Valdério Freire Moraes Júnior, Adriana Fernandes Vasconcelos, Claudia Gomes Graciano, Aneide Oliveira Araújo

condições de trabalho. Por fim, a análise dos custos evidenciou o quanto os gastos efetuados em relação à qualidade beneficiaram a organização.

Palavras-chave: Qualidade. Custos da qualidade. Turismo melhor.

\title{
Costs of the quality: the experience of a potiguar restaurant in Better Tourism
} Program

\begin{abstract}
Costs of the quality are usually related to prevention, internal flaws, external flaws and inspection. Those costs must be managed, and for this reason companies have been looking for the implementation of quality programs, for the purpose of improving your products and services, as well as to increase your profits. In that perspective, the present study has as objective to analyse the costs of quality of a Potiguar restaurant located in the city of Natal, that took part in the Better Tourism Program in 2006. It treats of a research of qualitative character about the mensuration of quality costs based on the fitted out period: January of 2006 to May of 2007. The data were obtained by means of semi-structured interview as well as accounting reports for verification of the existent connections among the variables that integrate the costs of quality of the company. The results show that to join to the certificate, it brought benefits to the entity, for a real reduction of errors noticed in the first semester of 2007, fixation in a market more and more competitive and better work conditions. Finally, the analysis of costs evidenced as expenses made in relation to quality benefited the organization.
\end{abstract}

Key Words: Quality. Costs of quality. Better tourism.

\section{INTRODUÇÃO}

O segmento de restaurantes tem crescido acentuadamente desde o final do século XX. O acesso a esse tipo de mercado é facilitado porque, na maioria dos casos, requer baixo volume de capital, propiciando a multiplicidade de unidades operacionais ou desenvolvimento de tecnologia própria.

Por outro lado, estão sujeitos às influências externas, pois podem ser altamente afetados por avanços tecnológicos, regulamentação governamental e aumento do preço da energia, que podem mudar os serviços, como também sua forma e o tamanho da estrutura da empresa de serviço (VENTURI, 2003). 
Custos da qualidade: a experiência de um restaurante potiguar no Programa Turismo Melhor Valdério Freire Moraes Júnior, Adriana Fernandes Vasconcelos, Claudia Gomes Graciano, Aneide Oliveira Araújo

Esta perspectiva requer uma gestão preocupada com os níveis tático e estratégico da organização, com vistas à operacionalização que visa o cumprimento da missão empresarial. Neste contexto, a busca pela qualidade constitui-se um aspecto relevante, tanto com relação ao seu ambiente interno quanto externo.

A despeito da multiplicidade de serviços oferecidos pelos restaurantes que surgem no mercado, algumas características em comum podem ser identificadas, tais como: intangibilidade, estocagem mínima, produção e consumo fisicamente unidos, entrada fácil no mercado e influências externas (SCHMENNER, 1999).

A intangibilidade ocorre porque o serviço oferecido não pode ser modificado, quer dizer, não há estoque de serviço; como também o consumo costuma ser quase simultâneo à sua produção, tornando-os fisicamente unidos e requer controle da qualidade em tempo real, fazendo com que o estoque seja o mais limitado possível.

A qualidade total geralmente está relacionada a quatro tipos de custos distintos: falhas internas, externas, prevenção e inspeção. Dos custos citados, o da prevenção deve ser gerenciado de forma efetiva, pois se todos os erros forem evitados previamente, as falhas internas e externas podem ser eliminadas e, consequentemente, os custos delas decorrentes.

Nesse contexto, as empresas têm atentado para a gestão estratégica da qualidade, que é uma abordagem da qualidade mais ampla do que as antecessoras. $\mathrm{Na}$ visão de Garvin (1992), essa abordagem está "intimamente ligada à lucratividade e aos objetivos empresariais básicos, mais sensíveis às necessidades da concorrência e ao ponto de vista do consumidor e, mais firmemente associada à melhoria contínua".

O Serviço Brasileiro de Apoio às Micro e Pequenas Empresas (SEBRAE) ao avaliar esses aspectos, criou um Programa de Qualidade em Serviços Turísticos que vem obtendo sucesso no Estado do Rio Grande do Norte, denominado Turismo Melhor.

Esse programa tem como princípio melhorar a qualidade nos serviços prestados por hotéis e restaurantes voltados ao setor de turismo, fazendo com que as empresas passem por uma avaliação técnica e por um processo contínuo de melhoria, consultoria e treinamento apropriados. Diante do exposto, a questão que emerge é: qual o impacto 
Custos da qualidade: a experiência de um restaurante potiguar no Programa Turismo Melhor Valdério Freire Moraes Júnior, Adriana Fernandes Vasconcelos, Claudia Gomes Graciano, Aneide Oliveira Araújo

nos custos da qualidade de um empreendimento que aderiu ao Programa Turismo Melhor?

O presente estudo tem como objetivo analisar os custos de qualidade de um restaurante localizado na cidade do Natal, que aderiu ao Programa Turismo Melhor em 2006. Trata-se de uma investigação de natureza qualitativa que visa proporcionar insights a respeito da mensuração dos custos de qualidade no setor de restaurantes com base no período de janeiro de 2006 a maio de 2007.

\subsection{A questão da qualidade e sua evolução}

A qualidade tem sido, há um período considerável de tempo, fonte de constante preocupação para as empresas, devido à competitividade imposta pela internacionalização dos mercados, o que tem ocasionado uma maior exigência dos consumidores em relação aos produtos e serviços.

O conceito de qualidade, de acordo com Wernke e Bornia (2000), não é novo, e tem evoluído ao longo do tempo. O que se pode considerar como recente é a preocupação com o processo, incluindo-se neste não só o fabril, mas todo aquele que envolve 0 atendimento e a satisfação dos consumidores.

Nos séculos XVIII e XIX, quando os produtos eram fabricados por artesãos e artífices, a inspeção dos produtos era feita de maneira informal, isto é, quando ocorria (GARVIN, 1992). A inspeção formal tornou-se necessária a partir do surgimento da produção em massa, sendo criado no início do século XIX um sistema de medidas, gabaritos e acessórios, para assegurar um processo de fabricação uniforme.

Em 1922, com a publicação de The Control of Quality in Manufactuing, de Radford, a qualidade foi percebida como função independente e como um quesito gerencial a ser observado. Em 1931, a partir da publicação de Economic Control of Quality of Manufactured Product, de Shewhart, foi conferido um caráter científico à disciplina, enfatizando a existência de variações na produção e criando formas de distinguir as variações aceitáveis daquelas que pudessem indicar problemas.

Em 1946 foi criada a Sociedade Americana de Controle da Qualidade (ASQC), que se consolidou como importante grupo profissional dominante da área. Já a partir 
Custos da qualidade: a experiência de um restaurante potiguar no Programa Turismo Melhor Valdério Freire Moraes Júnior, Adriana Fernandes Vasconcelos, Claudia Gomes Graciano, Aneide Oliveira Araújo

dos anos 1950 a publicação de diversas obras por autores como Juran, Feigenbaum e Crosby, marcou definitivamente a era da qualidade e a preocupação das empresas sobre esse aspecto de suas atividades.

$O$ entendimento sobre o que vem a ser qualidade diverge entre os autores que tratam do assunto, visto que esse aspecto envolve certo grau de subjetivismo por se tratar de um critério que deverá ser avaliado principalmente pelos clientes. Para Feigenbaum (apud Wernke e Bornia, 2000), qualidade é uma determinação do cliente e não uma determinação da engenharia, nem de marketing e nem da alta administração. Já na concepção de Crosby (apud Wernke e Bornia, 2000) qualidade é conformidade com os requisitos. Para Deming (apud Cordeiro, 2004), a qualidade seria representada pela melhoria contínua de produtos e processos, visando à satisfação dos clientes.

Segundo Gianesi e Corrêa (1994, p. 197),

o conceito de qualidade total fundamenta-se em algumas considerações importantes: todos na organização têm algo a contribuir para a qualidade final percebida pelo cliente; todos os custos relacionados com qualidade devem ser envolvidos nas análises; todo esforço bem direcionado de melhoria em qualidade repercute na competitividade; há sempre uma forma melhor de fazer as coisas e a qualidade deve ser construída ao longo do processo e não apenas verificada ao final.

$\mathrm{Na}$ ótica desses autores, todo esforço na empresa geralmente tem custos associados, porém esses podem ser relativamente pequenos se forem comparados com os custos de não se ter qualidade. Em décadas passadas a visão de qualidade levava em conta apenas as atividades de controle relacionadas à inspeção, fazendo com que os custos de qualidade fossem subavaliados; a única maneira, na época, de se melhorar esse problema era com mais inspeção e avaliação do responsável pela perda da qualidade, o inspetor.

Embora haja divergência entre os conceitos, é notável que a preocupação central relativa à qualidade esteja focada nas exigências e satisfação dos clientes, aos quais o produto ou serviço final é destinado, sendo avaliado pelos mesmos. Tendo em vista que 
Custos da qualidade: a experiência de um restaurante potiguar no Programa Turismo Melhor Valdério Freire Moraes Júnior, Adriana Fernandes Vasconcelos, Claudia Gomes Graciano, Aneide Oliveira Araújo

a continuidade e o lucro são objetivos de qualquer empresa, a qualidade então se torna um ponto imprescindível a ser observado pelos gestores.

Dessa forma, as empresas têm inserido a qualidade em todos os seus aspectos operacionais, incluindo-a no planejamento, elaboração de planos de ação, controle e acompanhamento de todas as áreas, porque perceberam que todo o processo é responsável por gerar produtos e serviços que correspondam às expectativas dos consumidores.

\section{AS DIMENSÕES DA QUALIDADE}

A qualidade não pode ser concebida como um aspecto individual, pois envolve várias dimensões possíveis em que se pode avaliá-la. Na concepção de Garvin (1992, p. 59-60) existem oito dimensões ou categorias da qualidade:

- Desempenho - se refere às operações básicas de um produto. Em um restaurante estaria relacionada à velocidade de atendimento ou não redução de filas de espera.

- Características - caracterizam-se como as características secundárias que suplementam o funcionamento básico do produto.

- Confiabilidade - está ligada a probabilidade de o produto funcionar mal ou de apresentar falhas em um dado momento. Essa dimensão está mais ligada a bens duráveis, já que exige a utilização do produto por um período de tempo.

- Conformidade - diz respeito ao grau em que o projeto e as características operacionais de um produto estão de acordo com os padrões que foram estabelecidos anteriormente à sua fabricação. Essa categoria engloba duas abordagens: a primeira que iguala a conformidade ao cumprimento das especificações e a segunda a relaciona com o grau de variabilidade em torno de uma dimensão estabelecida como meta ou de uma linha central.

- Durabilidade - está ligada a medida da vida útil do produto, podendo englobar, por exemplo, o uso proporcionado por um produto até ele se 
Custos da qualidade: a experiência de um restaurante potiguar no Programa Turismo Melhor Valdério Freire Moraes Júnior, Adriana Fernandes Vasconcelos, Claudia Gomes Graciano, Aneide Oliveira Araújo

deteriorar fisicamente, ou a utilização do produto antes de ele quebrar e a substituição ser considerada melhor que o reparo necessário.

- Atendimento - engloba a rapidez, cortesia e facilidade de reparo. Isso inclui a pontualidade no atendimento, o relacionamento com as pessoas responsáveis pelo atendimento ou a freqüência com que as chamadas não são atendidas, e ainda as normas de tratamento das reclamações da empresa.

- Estética - pode englobar a aparência de um produto, a sensação que causa: o sabor, som ou cheiro. A estética também está ligada as combinações de atributos que podem satisfazer as preferências do consumidor, e por esta razão pode ser considerada uma questão subjetiva.

- Qualidade percebida - são as medidas indiretas que interferem na avaliação da qualidade de um produto, a exemplo das imagens, propaganda, nome e reputação das marcas.

Cada dimensão pode ser considerada um ponto que merece planejamento e controle por parte dos gestores; e uma empresa que decida competir em qualidade não precisa buscar as oito dimensões de uma só vez, pois essa decisão poderia gerar preços muito altos. Garvin (1992, p.74) salienta que "desde que as dimensões estejam ajustadas às necessidades do mercado, a abordagem direcionada pode dar ótimos resultados". Sendo assim, a empresa pode optar por melhorar uma ou mais dimensões da qualidade, tornando-se competitiva, por se adequar ao que o mercado demanda.

É relevante atentar ainda para que os gestores não cometam erros, como o ataque direto ao líder em qualidade, ou a busca de dimensões que não têm importância para os consumidores. Isso pode ocorrer quando não se buscam as informações a respeito das oito dimensões da qualidade a partir das necessidades do mercado em potencial e dos clientes existentes. 
Custos da qualidade: a experiência de um restaurante potiguar no Programa Turismo Melhor Valdério Freire Moraes Júnior, Adriana Fernandes Vasconcelos, Claudia Gomes Graciano, Aneide Oliveira Araújo

\section{CUSTOS DA QUALIDADE}

A introdução da discussão a respeito dos custos na gestão da qualidade encontra seu início em 1951 com a publicação do livro de Joseph Juran intitulado Quality Control Handbook. Juran (1951) observou que para se atingir um determinado nível de qualidade os custos podiam ser divididos em custos evitáveis e inevitáveis, dentre outros aspectos.

A partir dessa publicação surgiram outras obras abordando o assunto, como "The Quality Manager and Quality Cost" de W.J. Masser em 1957; "How to put Quality Cost to Use" de Harold Freeman de 1960; e "Total Quality Control" escrito pelo Dr. Armand V. Feigenbaum, com um capítulo inteiramente dedicado aos custos da qualidade em 1961. (ZILLI, 2003)

Com a implantação das normas ISO, mediante a criação da International Organization for Standardization, os gestores sentiram a necessidade de tratar os custos da qualidade de forma mais sistemática, contribuindo para a melhoria e medição da qualidade em seus empreendimentos.

O conceito de custos da qualidade, na concepção de Campanela (apud Zilli, 2003), são os custos que representam a diferença entre o custo atual de um produto ou serviço e o custo ideal, se não houvesse o serviço fora do padrão, falha de produtos ou defeitos na manufatura.

Feigenbaum (apud Robles Jr., 2003, p.58) salienta que atualmente os custos da qualidade podem ser equiparados, em termos de importância, aos demais custos que são preocupação central nas empresas, a exemplo dos custos com mão-de-obra, engenharia e de vendas.

No quadro 1 pode se observar, do ponto de vista da qualidade total, os tipos de custos existentes além do custo da inspeção. O custo da prevenção é o primeiro a ser trabalhado, pois se todos os erros forem evitados de forma prévia, as falhas internas e externas poderiam ser eliminadas. Dessa forma, as empresas devem entender que dois tipos de custos, o de prevenção e inspeção, estão sob o controle da gerência, 
Custos da qualidade: a experiência de um restaurante potiguar no Programa Turismo Melhor Valdério Freire Moraes Júnior, Adriana Fernandes Vasconcelos, Claudia Gomes Graciano, Aneide Oliveira Araújo

enquanto as falhas internas e externas, por sua vez, são conseqüências das decisões gerenciais que foram tomadas.

Os quatro tipos de custos de qualidade evidenciados no quadro 1 podem ser interpretados da seguinte forma: um aumento inicial dos custos de prevenção pode repercutir em uma diminuição dos custos de falhas internas, como também um menor nível de inspeção será necessário. Daí pode se observar que os custos totais antes do esforço da qualidade total são bem maiores no primeiro momento, que os custos totais depois do esforço de se ter qualidade total em um segundo momento (BRINKER, 2000; GARRISON; NOREEN, 2001; HANSEN; MOWEN, 2001). 
Custos da qualidade: a experiência de um restaurante potiguar no Programa Turismo Melhor Valdério Freire Moraes Júnior, Adriana Fernandes Vasconcelos, Claudia Gomes Graciano, Aneide Oliveira Araújo

\begin{tabular}{|c|c|}
\hline Tipos de custos de qualidade & Exemplos em serviços \\
\hline $\begin{array}{l}\text { Custos de todas as atividades que visam } \\
\text { impedir, preventivamente, os erros de } \\
\text { ocorrerem. }\end{array}$ & $\begin{array}{l}\text { - treinamento e desenvolvimento de pessoal } \\
\text { - Manutenção preventiva de equipamento de } \\
\text { processo } \\
\text { - desenvolvimento e implantação de projetos de } \\
\text { melhoria de qualidade } \\
\text { - avaliação e desenvolvimento de fornecedores } \\
\text { - desenvolvimento e implantação de auditorias do } \\
\text { sistema de qualidade } \\
\text { - aferição de instrumentos de medição } \\
\text { - desenvolvimento de sistemas à prova de falhas }\end{array}$ \\
\hline $\begin{array}{c}\text { Custos de inspeção: } \\
\text { Custos de todas as atividades que visam } \\
\text { checar se erros ocorreram, depois de a } \\
\text { atividade, serviço ou produto ter sido } \\
\text { executado. }\end{array}$ & $\begin{array}{c}\text { - inspeção e teste de material comprado } \\
\text { - inspeção e testes ao longo do processo } \\
\text { - inspeção e testes do resultado do serviço } \\
\text { prestado } \\
\text { - operação de sistemas de controle do processo } \\
\text { - sistemas de avaliação da qualidade do serviço } \\
\text { pelo cliente } \\
\end{array}$ \\
\hline $\begin{array}{l}\text { Custos de falhas internas: } \\
\text { Custos de todas as atividades que visam lidar } \\
\text { com erros que ocorreram e foram detectados } \\
\text { enquanto o cliente ou seu bem ainda estão na } \\
\text { organização }\end{array}$ & $\begin{array}{l}\text { - refazer de imediato um serviço mal prestado } \\
\text { - refugos e re-trabalhos em bens do cliente por } \\
\text { falhas na prestação do serviço } \\
\text { - reorganizar processos e procedimentos após a } \\
\text { falha } \\
\text { - diagnóstico das causas das falhas } \\
\text { - custos com recuperação do cliente }\end{array}$ \\
\hline $\begin{array}{l}\text { Custos de falhas externas: } \\
\text { Custos de todas as atividades que visam lidar } \\
\text { com erros que ocorreram e foram notados } \\
\text { depois que os serviços foram prestados e o } \\
\text { cliente ou seu bem já deixou a organização }\end{array}$ & $\begin{array}{c}\text { - garantia do serviço } \\
\text { - re-trabalho e re-serviço } \\
\text { - responsabilidade civil por falhas no serviço } \\
\text { prestado } \\
\text { - gerenciamento de reclamações } \\
\text { - perda de fidelidade do cliente, afetando futuros } \\
\text { negócios } \\
\text {-testemunho desfavorável do cliente insatisfeito a } \\
\text { outros clientes em potencial }\end{array}$ \\
\hline
\end{tabular}

Quadro 1 - Tipos de custos de qualidade

Fonte: Adaptado de Gianesi e Corrêa (1994, p. 199).

Após serem identificados, é preciso que os custos da qualidade possam ser mensurados permitindo, de acordo com Robles Júnior (2003): avaliar programas da qualidade; fixar objetivos relativos aos programas da qualidade; conhecer as perdas decorrentes da falta de qualidade; conhecer a distribuição dos custos pelas categorias de custos da qualidade, visando direcionar investimentos relativos à melhoria da qualidade, dentre outros objetivos que podem ser alcançados.

A mensuração dos custos da qualidade pode proporcionar acréscimo nos lucros em virtude de aspectos como: melhor uso dos recursos existentes; aumento da 
Custos da qualidade: a experiência de um restaurante potiguar no Programa Turismo Melhor Valdério Freire Moraes Júnior, Adriana Fernandes Vasconcelos, Claudia Gomes Graciano, Aneide Oliveira Araújo

produtividade; melhor utilização de relatórios gerenciais; avaliação dos investimentos; maior facilidade para elaboração de orçamento de custos da qualidade, com o conhecimento de quais categorias precisam de mais investimentos e auxílio na avaliação da gestão da qualidade.

Contemplar os custos da qualidade na gestão da empresa, tanto no que diz respeito à identificação quanto à mensuração, torna-se uma atividade de fundamental importância para a empresa que deseja atender melhor aos aspectos de qualidade requeridos pelos clientes, refletindo-se nos resultados que a empresa pode alcançar.

\section{CONCEITO DE RESTAURANTE}

Segundo Castelli (2001, p. 297),

considera-se restaurante o estabelecimento que fornece ao público alimentação mediante pagamento. Esse conceito engloba os mais variados tipos de estabelecimentos. Cada um deles, contudo, possui características específicas em função das quais são mais precisamente definidas.

As pessoas, ao irem a um restaurante, esperam ter um serviço de qualidade, não somente por pagarem pela alimentação, mas pelo ambiente que escolheram. Assim sendo, cada estabelecimento acaba tendo uma característica peculiar para que possa agradar os mais variados tipos de clientes, como também atender uma determinada classe social.

Todo restaurante tem um conceito de forma a oferecer uma impressão que seja peculiar. A imagem dele atrai certo público, seja de crianças, casais, pessoas que irão celebrar ocasiões especiais. Para tanto, o conceito deverá se adequar ao local para que possa alcançar um público alvo formal ou casual, por meio da localização, cardápio e decoração (WALKER; LUNDBERG, 2003).

Os restaurantes podem ser classificados de diversas maneiras. Ao classificar por categoria do tipo: primeira categoria, segunda categoria e terceira categoria, eles utilizam-se de símbolos como garfos, por exemplo. Geralmente, essa simbologia é colocada nas entradas desses estabelecimentos para orientar seus clientes, que são os 
Custos da qualidade: a experiência de um restaurante potiguar no Programa Turismo Melhor Valdério Freire Moraes Júnior, Adriana Fernandes Vasconcelos, Claudia Gomes Graciano, Aneide Oliveira Araújo

responsáveis em avaliar todos os requisitos relacionados à qualidade (CASTELLI, 2001).

Conforme Walker e Lundberg (2003, p. 66),

muitos restaurantes não possuem conceitos claros ao seu respeito. Sua imagem, os produtos, o serviço e todos aqueles itens que compõem a atmosfera de um restaurante não integram um conjunto harmonioso atrativo. Os símbolos de identificação, a sinalização, os uniformes, os cardápios e a decoração devem estar em sintonia, para formar uma imagem bem definida para o público.

Do exposto, pode se observar que os restaurantes trabalham com símbolos expressando, muitas vezes, o serviço oferecido e que precisa estar bem sinalizado. Alguns estabelecimentos se preocupam em ter um ambiente relacionado ao bem-estar do seu cliente, principalmente no que se trata do produto que vai ser consumido.

Por fazer parte da sociedade moderna, esse tipo de empresa pode atrair clientes que vão de um simples lazer a negócios relevantes, fazendo com que o local seja apropriado para servir a essas pessoas, mediante atributos físicos, intelectuais, profissionais e morais (CASTELLI, 2001).

\section{PROCEDIMENTOS METODOLÓGICOS}

Para Salomon (1999, p. 152), "o termo pesquisa será genericamente assumido como trabalho empreendido metodologicamente, quando surge um problema, para qual se procura a solução adequada dessa natureza científica". Para solucionar um problema, portanto, é preciso estabelecer um método de pesquisa. Cervo e Bervian (1983, p.23) afirmam que "em seu sentido mais geral, o método é a ordem que deve impor aos diferentes processos necessários para atingir um fim dado ou um resultado desejado".

O artigo é resultado de uma metodologia que se utiliza de uma revisão da literatura, apresentando estudos empíricos existentes em um novo contexto, de forma 
Custos da qualidade: a experiência de um restaurante potiguar no Programa Turismo Melhor Valdério Freire Moraes Júnior, Adriana Fernandes Vasconcelos, Claudia Gomes Graciano, Aneide Oliveira Araújo

comparativa, como também analítica, contendo abordagens relevantes para dar embasamento ao estudo de caso (BEUREN, 2004).

Nesse sentido, foi efetuado um estudo de caso em um restaurante chinês situado na cidade do Natal, que implantou o programa Turismo Melhor no ano de 2006. Para consecução dos dados necessários foi efetuada uma entrevista semi-estruturada junto ao proprietário da empresa, com aplicação de questionário. A escolha da empresa se deu por acessibilidade e a disponibilidade dos sócios em fornecer informações relevantes através do instrumento respondido e das 17 observações fornecidas com base em seus relatórios contábeis.

O estudo caracteriza-se como descritivo, pois na concepção de Gil (2002) busca descrever as características de determinada população ou fenômeno. Esse fenômeno está ligado aos custos da qualidade do restaurante pesquisado, utilizando-se de uma análise comparativa para confirmação dos dados.

Quanto à modalidade, trata-se de uma pesquisa bibliográfica e documental. A primeira serviu para informar o contexto no qual surge a necessidade do estudo dos custos da qualidade nas empresas de forma geral. A pesquisa documental foi utilizada no exame dos relatórios contábeis da empresa, na busca das informações necessárias para fundamentar o estudo, que tem natureza qualitativa.

\section{CASO DO RESTAURANTE CHINÊS}

O restaurante estudado é do tipo chinês no qual, que conforme Walker e Lundberg (2003, p. 53), "a comida gira em torno de uma wok, uma grande panela de metal com uma base arredondada. $O$ formato da panela concentra o calor no fundo; os alimentos são cortados uniformemente em pequenos pedaços e cozidos em pouco tempo".

Geralmente, este tipo de restaurante é proveniente de famílias chinesas que se instalaram em várias partes do mundo, tendo como diferencial a comida permanecer aquecida durante o consumo, além de grandes porções a preços acessíveis. 
Custos da qualidade: a experiência de um restaurante potiguar no Programa Turismo Melhor Valdério Freire Moraes Júnior, Adriana Fernandes Vasconcelos, Claudia Gomes Graciano, Aneide Oliveira Araújo

A empresa pesquisada, Restaurante Chinês, localizada na Cidade do Natal, tem 6 anos no mercado e atualmente possui 38 funcionários. Seu horário de funcionamento é das 11 às 16 horas, atendendo somente no horário do almoço, diariamente, com capacidade máxima de 400 lugares. Sua taxa de ocupação diária é em média de 380 pessoas, distribuídas no seu tempo de atendimento, já que se trata da modalidade selfservice, sendo que o cliente permanece em média 1 hora durante o seu almoço. Seu objetivo é atender os clientes, buscando o aperfeiçoamento contínuo do serviço prestado.

O Programa Turismo Melhor, conforme o site do SEBRAE-RN (2007), avaliou a empresa cumprindo as seguintes etapas:

1) Avaliação inicial feita por auditores para verificar como a empresa está estruturada.

2) Apresentação das não-conformidades ou lacunas que foram identificadas na primeira etapa.

3) Sugestão da implementação de ajustes e melhorias que serão necessárias.

4) Avaliação final realizada nas dependências da empresa.

5) Por último, os relatórios serão consolidados e entregues ao Grupo Gestor do Programa para fazer uma validação final.

Semestralmente, a empresa será submetida a uma auditoria para que seja avaliada a sua continuidade no Programa.

O diagnóstico do Programa Turismo Melhor concluiu que o principal diferencial é a qualidade encontrada no estabelecimento, provavelmente em decorrência de uma preocupação crescente dos gestores em ter seus colaboradores sempre se reciclando, participando de eventos e cursos de capacitação e motivação, para melhorar suas funções, consequentemente das atividades executadas.

No entanto, apresentou pequenas falhas no salão de atendimento as quais já foram reparadas, o que representou um gasto em torno de cinco mil reais. As recomendações dos auditores do programa foram as seguintes: fazer pequenos reparos nas suas instalações como: pintura, torneiras, utensílios e lâmpadas. Quanto à 
Custos da qualidade: a experiência de um restaurante potiguar no Programa Turismo Melhor Valdério Freire Moraes Júnior, Adriana Fernandes Vasconcelos, Claudia Gomes Graciano, Aneide Oliveira Araújo

disposição dos alimentos no self-service, foi sugerido que houvesse uma melhora na iluminação e identificação dos pratos para ajudar o serviço próprio do cliente.

Ao aderir ao selo, o restaurante se responsabilizou em manter o padrão de qualidade exigido da seguinte forma: trabalhando fatores internos relacionados à sua estrutura, avaliando seu quadro de colaboradores, apresentando um diferencial no mercado e trabalhando na prevenção permanente. Procurando melhorar a qualidade, focou a atenção nas seguintes dimensões:

a) Desempenho e características com uma produção de alta qualidade e fácil disposição dos produtos para serem servidos pelos clientes.

b) Atendimento: maior agilidade na recolocação dos alimentos que vão faltando, e melhor atendimento aos clientes nas mesas, para pedidos de refrigerantes, sucos ou sobremesas.

c) Estética: os detalhes com decoração de mesas, assim como do estabelecimento, como pintura e iluminação são freqüentemente percebidos. Com isso busca-se também melhorar outra dimensão da qualidade: a qualidade percebida dos clientes.

\section{ANÁLISE DOS CUSTOS DA QUALIDADE}

Os dados dos custos ou despesas relacionadas à prevenção, inspeção, falhas internas e falhas externas foram obtidos, conforme a tabela 1, com base nas informações fornecidas pela empresa. Os dados são dos custos de qualidade da empresa referente ao período de janeiro de 2006 a maio de 2007.

A análise evidencia que depois da implementação do Programa Turismo Melhor, em novembro de 2006, os gastos médios mensais com prevenção de $R \$ 4.699,15$ continuam a serem os mais significativos crescendo de $62 \%$ para $73 \%$ do montante médio mensal. Por outro lado, observa-se que os gastos médios mensais relacionados a falhas internas de $R \$ 1.923,04$ e falhas externas de $R \$ 449,68$, foram reduzidos em $14 \%$ e $3 \%$, respectivamente, conforme Figura 1. 
Custos da qualidade: a experiência de um restaurante potiguar no Programa Turismo Melhor Valdério Freire Moraes Júnior, Adriana Fernandes Vasconcelos, Claudia Gomes Graciano, Aneide Oliveira Araújo

Observou-se, também, que embora tenha crescido em termos absolutos, acompanhando o comportamento da média do custo total da qualidade, os gastos com avaliação aumentaram o equivalente a $6 \%$ do total.

Tabela 1 - Custos da Qualidade no período de janeiro/2006 a maio/2007

\begin{tabular}{|c|c|c|c|c|c|}
\hline \multirow{2}{*}{ Meses } & \multicolumn{4}{|c|}{ Custos da qualidade } & Custos \\
\cline { 2 - 5 } & Prevenção & Falhas Internas & Falhas Externas & Avaliação & totais \\
\hline Janeiro/06 & 4378,81 & 2283,68 & 486,53 & 400,00 & 8219,02 \\
\hline Fevereiro/06 & 4032,36 & 2124,58 & 476,80 & 404,00 & 8707,14 \\
\hline Março/06 & 4665,27 & 1855,77 & 467,26 & 408,04 & 8066,34 \\
\hline Abril/06 & 4245,97 & 1855,77 & 457,92 & 412,12 & 8641,78 \\
\hline Maio/06 & 4186,52 & 1997,60 & 448,76 & 416,24 & 8719,12 \\
\hline Junho/06 & 4957,54 & 2318,45 & 439,79 & 420,40 & 8806,18 \\
\hline Julho/06 & 4376,80 & 2327,69 & 430,99 & 424,61 & 8230,09 \\
\hline Agosto/06 & 5108,76 & 1516,70 & 422,37 & 428,85 & 8476,68 \\
\hline Setembro/06 & 5281,83 & 1743,00 & 413,92 & 433,14 & 8871,90 \\
\hline Outubro/06 & 5860,77 & 1685,89 & 405,64 & 437,47 & 8389,78 \\
\hline Novembro/06 & 4596,06 & 1444,34 & 397,53 & 441,85 & 8879,78 \\
\hline Dezembro/06 & 7053,61 & 991,51 & $\mathbf{2 5 8 , 2 2}$ & $\mathbf{6 6 2 , 7 7}$ & 9135,87 \\
\hline Janeiro/07 & 7025,61 & 875,36 & 215,32 & 894,74 & 9857,89 \\
\hline Fevereiro/07 & 6053,33 & 919,58 & 202,40 & 1118,43 & 9909,74 \\
\hline Março/07 & 5623,54 & 792,27 & 189,34 & 1398,04 & 9622,87 \\
\hline Abril/07 & 6438,13 & 879,12 & 179,54 & 1607,74 & 9233,20 \\
\hline Maio/07 & 6920,24 & 919,21 & 177,87 & 1205,81 & 9834,28 \\
\hline
\end{tabular}

Fonte: Dados fornecidos pela empresa

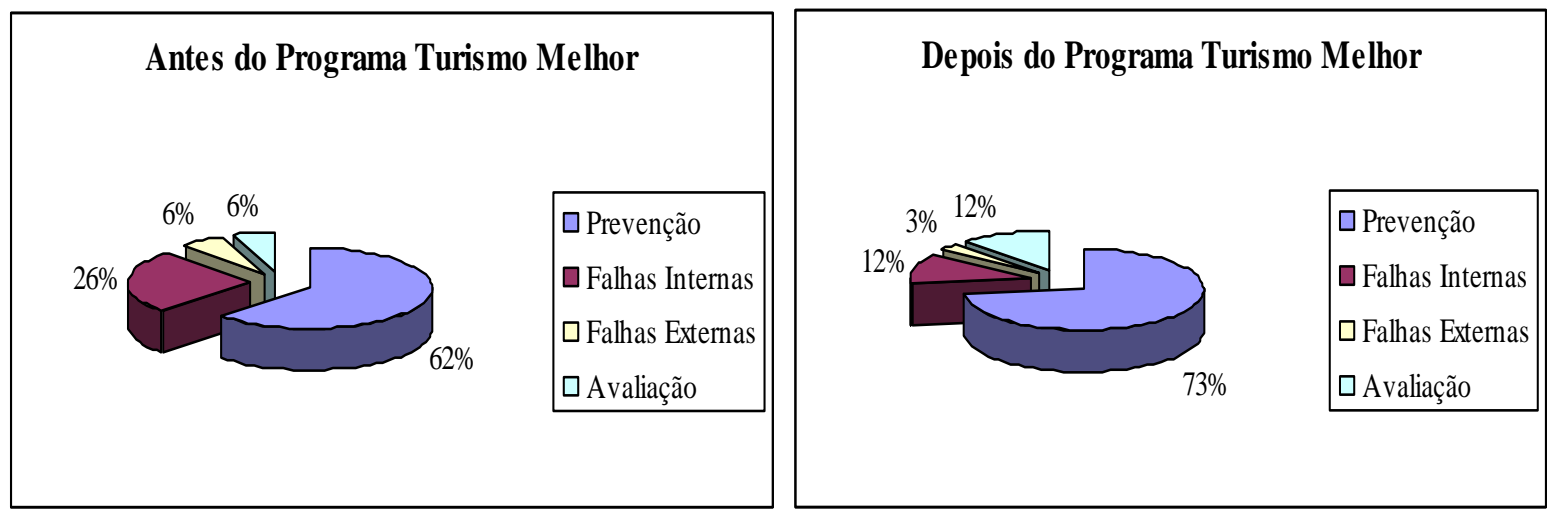

Figura 1 - Comparação entre os custos da qualidade do restaurante chinês

Fonte: dados da pesquisa 
Custos da qualidade: a experiência de um restaurante potiguar no Programa Turismo Melhor Valdério Freire Moraes Júnior, Adriana Fernandes Vasconcelos, Claudia Gomes Graciano, Aneide Oliveira Araújo

Em face da reduzida série observada não foi possível confirmar o que preconiza a literatura, mas espera-se que em longo prazo, à medida que se aumente o custo com prevenção e avaliação, ocorra redução significativa nos custos de falhas internas e externas, reduzindo o custo total (BRINKER, 2000; GARRISON; NOREEN, 2001; HANSEN; MOWEN, 2001).

\section{CONSIDERAÇÕES FINAIS}

A qualidade é uma característica de produtos e serviços discutida desde o século passado. Atualmente, mais que em qualquer outra época, este tem sido um fator de crescente preocupação nas empresas, pois os clientes a têm exigido cada vez mais. Para sobressair-se num mercado tão exigente e competitivo, portanto, gerenciar a qualidade tem sido uma necessidade vital.

Esse estudo teve como objetivo analisar os custos de qualidade de um restaurante localizado na cidade do Natal, que aderiu ao Programa Turismo Melhor em 2006. Para tanto, buscou identificar e classificar os principais custos de qualidade: avaliação, prevenção, falhas internas e falhas externas, como também sobre a realidade dos restaurantes, através do referencial teórico, como também observar o comportamento dos custos da qualidade.

A avaliação dos custos da qualidade permitiu identificar na empresa qual foi o investimento em qualidade, bem como evidenciar as melhorias alcançadas e a correspondência em custos decorrentes da implementação das recomendações do Programa Turismo Melhor, que se torna um diferencial do restaurante em relação aos seus concorrentes.

Por meio dos dados obtidos, tornou-se possível avaliar o impacto do Programa Turismo Melhor, evidenciar o comportamento dos custos, principalmente na prevenção e avaliação, para diminuir cada vez mais as falhas internas e externas.

O Restaurante Chinês, por ter gestores que desde o início de suas atividades sempre tiveram preocupações com a qualidade, teve que adequar apenas alguns aspectos exigidos pelo programa. Aderir ao selo trouxe benefícios à entidade, pela 
Custos da qualidade: a experiência de um restaurante potiguar no Programa Turismo Melhor Valdério Freire Moraes Júnior, Adriana Fernandes Vasconcelos, Claudia Gomes Graciano, Aneide Oliveira Araújo

redução efetiva de falhas percebidas no primeiro semestre de 2007 , fixação em um mercado cada vez mais competitivo e melhores condições para buscar o aumento dos lucros.

Apesar de ter o selo Turismo Melhor há apenas 6 meses, percebe-se o quanto os custos foram modificados, aumentando a proporção dos relacionados à prevenção, principalmente, em se tratando do Restaurante Chinês que já se preocupava com qualidade desde o início do seu funcionamento. Na verdade, o empreendedor espera que a empresa melhore seu resultado financeiro como também o controle relacionado à diminuição de sobras, que, pelo fato de ser um self-service, é uma constante e atualmente é doada para alimentação de animais em uma fazenda.

A reduzida quantidade de observações, especialmente depois da intervenção de melhoria, considerando que a empresa já praticava ações de melhoria contínua, não permitiu uma análise de tendência do comportamento dos quatro tipos de custos da qualidade, o que é recomendável para que haja o monitoramento dos avanços esperados pela gestão da empresa.

\section{REFERÊNCIAS}

BEUREN, Ilse Maria (org). (2004). Como elaborar trabalhos monográficos em contabilidade: teoria e prática. (2 ed.). São Paulo: Atlas.

BRINKER, Barry J. (2000). Guide to Cost Management. - New York: John Wiley and Sons.

CASTELLI, Geraldo. (2001). Excelência em Hotelaria: uma abordagem prática. (9 ed.). Rio de Janeiro, Qualitymark.

CERVO, Amado Luiz; BERVIAN, Pedro Alcino. (1996). Metodologia científica. (4 ed.). São Paulo: MAKRON, Books.

CORDEIRO, José Vicente B. de Mello. (2004). Reflexões sobre a Gestão da Qualidade Total: fim de mais um modismo ou incorporação do conceito por meio de novas ferramentas de gestão? Revista FAE, Curitiba, v.7, n.1, p.19-33, jan./jun.

FERREIRA, Aurélio Buarque de Holanda. (1988). Minidicionário Aurelio. (2 ed.). Rio de Janeiro: Nova Fronteira. 
Custos da qualidade: a experiência de um restaurante potiguar no Programa Turismo Melhor

Valdério Freire Moraes Júnior, Adriana Fernandes Vasconcelos, Claudia Gomes

Graciano, Aneide Oliveira Araújo

GARVIN, David A. (1992). Gerenciando a qualidade. Rio de Janeiro: Qualitymark.

GARRISON, Ray H. e NOREEN, Eric W. (2001). Contabilidade Gerencial. (9 ed.). Rio de Janeiro: LTC.

GIANESI, Irineu G. N; CORRÊA, Henrique Luiz. (1994). Administração estratégica de serviços. São Paulo: Atlas.

GIL, Antônio Carlos. (2002). Como elaborar projetos de pesquisa. (4 ed.). São Paulo: Atlas.

GUJARATI, Damodar. (2006). Econometria básica. (4 ed.). Trad. Maria José Cyhlar Monteiro. Rio de Janeiro: Elsevier.

HANSEN, Don R. e MOWEN, Maryanne M. (2001). Gestão de Custos: Contabilidade e Controle. São Paulo: Pioneira.

ROBLES JÚNIOR, Antônio. (1994). Custos de Qualidade: uma estratégia para a competição global. São Paulo: Atlas.

SCHMENNER, Roger W. (1999). Administração de operações em serviços. São Paulo: Futura.

SALOMON, Délcio Vieira. (1999). Como fazer uma monografia. (9 ed.). São Paulo: Martins Fontes.

SEBRAE. Serviço de Apoio às Micro e Pequenas Empresas. Disponível em: http://www.sebrae.com.br. Acesso em: 03/jul/2007.

SEBRAE RN. Regulamento do Programa Turismo Melhor. Disponível em: http://www.sebraern.com.br. Acesso em: 06/jul/2007.

SILVESTRO, R. J.; FITZGERALD, L.; JOHNSTON, R.; VOSS, C. (1992). Towaards a classification of service processes. International Journal of Service Industry Management, v. 3, n. 3. p. 62-75.

VENTURI, James Luiz. (2003). Estudo das características empreendedoras dos proprietários de restaurantes na cidade de Itapema, conforme a abordagem de David McClelland. 93p. (Dissertação de Mestrado). Universidade do Vale do Itajaí, Santa Catarina.

WALKER, John R.; LUNDBERG, Donald E. (2003). O restaurante. (3 ed.). Porto Alegre: Bookman. 
Custos da qualidade: a experiência de um restaurante potiguar no Programa Turismo Melhor Valdério Freire Moraes Júnior, Adriana Fernandes Vasconcelos, Claudia Gomes Graciano, Aneide Oliveira Araújo

WERNKE, Rodney e BORNIA, Antonio Cezar. (2000). Considerações acerca dos Conceitos e Visões sobre os Custos da Qualidade. Revista FAE, Curitiba, v.3, n.2, p.7788, maio/ago.

WERNKE, Rodney. (1999). Relatórios gerenciais aplicáveis aos custos de falhas internas. (Dissertação de Mestrado). Universidade Federal de Santa Catarina. Florianópolis.

ZILLI, Carlos Afonso. (2003). Desenvolvimento de um modelo de melhoria de processos e projetos com base no gerenciamento dos custos da qualidade em um ambiente de gestão por atividades. (Dissertação de Mestrado). Universidade Federal de Santa Catarina. Florianópolis.

Data de Submissão: 24/05/2009

Data de Aceite: 17/06/2009 